\title{
Ophthalmologica at a Glance
}

\section{Ophthalmologica}

Ophthalmologica 2008;222:63

DOI: $10.1159 / 000115668$

\section{Phacoemulsification in Pseudoexfoliation Syndrome}

Arsen Akinci, Cosar Batman, Orhan Zilelioglu

Ophthalmologica 2008;222:112-116

In a large well-designed study, Akinci et al. have shown that they had no increase in surgical complications in association with pseudoexfoliation syndrome when looking at phacoemulsification in comparison to those patients without pseudoexfoliation. The one positive finding they did come up with is a significantly elevated intraocular pressure on the first postoperative day, which is not surprising in that we know these patients are prone to pseudoexfoliation glaucoma. Previous studies have shown an increased incidence of surgical complications, and yet pseudoexfoliation has not somehow become a different problem today from what it was $10-20$ years ago. What this most likely represents is the improvement in surgical technique which allows otherwise difficult cases to be more easily taken care of without complications. While the authors did not run into any situation with extreme zonule laxity and difficulty, with enough pseudoexfoliation cases this can occur and can be a very difficult problem at the time of surgery. In a series this size, however, it would appear that with a good cutting edge technique one need not be concerned about unusual complications with pseudoexfoliation.

\section{Comparison of the Infiniti Vision and the Series 20,000 Legacy Systems}

\author{
Luis E. Fernández de Castro, Kerry D. Solomon, Daniel J. Hu, \\ David T. Vroman, Helga P. Sandoval
}

Ophthalmologica 2008;222:96-99

Castro et al. compared the new Infiniti with the older 20,000 Legacy phacoemulsification system to see if the improved fluidics of the Infiniti made a difference in regard to the overall efficient use of ultrasound as well as the amount of irrigating fluid used. Because the more aggressive parameters with the Infiniti were at higher flow rates, it is possible that this may result in increased overall fluid flow. In contrast, they found both a statistically and clinically significantly decreased ultrasound time as well as amount of fluid used with the more aggressive parameters possible with the Infiniti system. New technology is only effective to the extent it improves clinical outcomes. While this study did not have the power or the ability to state that these results made a difference in regard to the eventual visual outcome of the patients, it did show that the newer parameters resulted in less use of ultrasound and balanced salt solution, both of which are important parameters for us to measure. Ultrasound is the most dangerous thing that we do during phacoemulsification lens removal and, therefore, reducing that parameter would seem to be a plus. Also the amount of irrigating fluid through the eye, although in general well tolerated, is best kept to a minimum, and, therefore, this would also seem to be a plus. So in a straightforward study, it would appear that, indeed, the new technology had measurable improvements in regard to the ultrasound and fluid needed to remove standard cataracts.

Randall J. Olson, MD, Salt Lake City, Utah

\begin{tabular}{ll}
\hline KARGER & ( ) 2008 S. Karger AG, Basel \\
0030-3755/08/2222-0063\$24.50/0 \\
$\begin{array}{l}\text { Fax +41 61 306 } 1234 \\
\text { E-Mail karger@karger.ch } \\
\text { www.karger.com }\end{array}$ & $\begin{array}{l}\text { Accessible online at: } \\
\text { www.karger.com/oph }\end{array}$
\end{tabular}

